\title{
Dorsopathy in urban public transport drivers in relation to occupational risks and workloads
}

\author{
Delia Mihăilă ${ }^{1},{ }^{*}$ Raluca Maria Iordache $^{1}$, and Viorica Petreanu ${ }^{1}$ \\ ${ }^{1}$ National Research and Development Institute for Occupational Safety and Health "Alexandru \\ Darabont"
}

\begin{abstract}
Drivers in urban public transport are exposed to specific risks and workloads with both somatic and psychological effects on their health. The most common somatic disorders are musculoskeletal diseases (MSDs), especially those of the spine, and some of them can be occupational diseases. The present paper represents a sequence from an ample study that has followed the effects of this professional activity on work aptitude and workers' state of health and then has established prevention measures, respectively measures for reduction of identified risk factors. An ergonomic, complex and multidimensional methodology has been used. The health state analysis has been performed through a prevalence, cross-sectional study on three cohorts (bus, tram, trolleybus drivers). In all groups, a high percentage of spinal pathology has been found, especially lumbosacral. The highest percentage of dorsopathies has been registered in the group of the trolleybus drivers $(48 \%)$, followed by the tram (43\%) and the bus (42\%). In all three cohorts, a significant percentage in disc herniation in the age group 36-45 years old has been found, which can indicate premature wear. The identification of occupational risk factors has allowed for the establishment of a set of prevention / reduction measures.
\end{abstract}

\section{Introduction}

Musculoskeletal disorders (MSDs) are the most frequent pathology encountered by public transport drivers. In relation with the prolonged sitting posture, ergonomic deficiencies of the driving post, duration of driving, vehicle type, road condition, diverse vertebral column pathology, especially in the lumbar spine, is observed. [1] These MSDs increase with the annual mileage. Work-related risks and their effects on health have to be correlated with the type of driver's career; if, for example, he previously worked on trucks, made manual loads handling, and then became a public transport driver, his risk for MSDs is increased.

The most common cause of work disability is an injury to the back or upper extremity. Repetitive, heavy and time-pressured activities are notorious contributors, as are cold and vibrations. [2] Low back pain is the number one cause of years lived with disability in USA, and the most common cause of disability in patients under the age of 45; neck pain is the number four cause of years lived with disability. [2-3] In the USA, the anual prevalence of low back pain is $15-45 \%$. [3]

The present study is a sequence from a larger ergonomic one, which aims to highlight the risk and workload factors for public transport drivers and their main effects on health, the evaluation of workload, work related stress, and the establishment of prevention measures / reduction of identified risk factors. The related to occupational risks and workloads health status of 201 bus drivers, 127 tram drivers and 64 trolleybus drivers selected on age, gender, seniority and seniority at work criteria was analyzed through a cross-sectional, prevalence

*Corresponding author: diacris8@gmail.com. 
study. Regarding the age of participants, the most consistent category was 41-50 years old in all three studied groups. Regarding the seniority, for the majority of participants it was between 20 and 30 years.

The situation on which the present study is grafted is as follows:

- $\quad$ Between the years 2002-2017, by studying the days of medical leave with temporary incapacity for work, vertebral column MSDs represented the main pathology responsible.

- If in 2004 the percentage of MSDs with temporary incapacity for work was around $20 \%$, in 2017 it became over $30 \%$

- Between 2011-2016 the highest percentage of MSDs with temporary incapacity for work was for trolleybus drivers (around 39\%), followed in descending order by tram drivers (around 38\%) and bus drivers (around 36\%). In 2017 the percentage of MSDs with temporary incapacity for work for bus drivers was $35.9 \%$ while for drivers of electric transport (trolleybus and tram) was 32.5\%.

\section{Background}

Drivers' work related MSDs have a higher prevalence than that encountered in the general population. The vertebral column MSDs prevalence is equally increased in men and women drivers compared to the general population mainly because of the augmentation in lumbar spine pathology. [4]

Dorsopathies, especially in the lumbar spine, are the combined effect of chronic biomechanical factors (e. g. whole body vibrations, prolonged sitting, bending up and down, twisting, repetitive movements; whole body vibration caused by driver's cabin vibration can also have an effect on cognitive faculties such as the vision, coordination and the overall functional ability of the workers) and acute ones (e.g. sudden inappropriate lifting, twisting), ergonomic deficiencies of the driving post, and psychosocial risk factors (e.g. increased work pressure and workload, long working days and weeks, varying working hours, low control, low job satisfaction). [1, 5]

Drivers have a $40 \%$ higher risk of developing cervical spine MSDs than other workers, although this MSDs' localization is less frequent than that of the lumbar spine. It seems that drivers' cervical spine pathology is in a smaller degree related to exposure to vibrations and more to the postural contractures. (After applying measures for reduction of drivers' exposure to vibration, the prevalence of lumbar spine MSDs decreased, while that of cervical spine MSDs' remained stable) [4]

Individual risk factors also play a role in producing vertebral column MSDs. In a crosssectional study, bus drivers over 50 years old tended to have a lower risk $(25 \%$ decrease in risk with each 10 years of age) for developing lumbar spine pathology then those under 40 , but when the pathology exists, it is more severe in drivers over 50 years old. The risk of developing cervical spine pathology was two times smaller in drivers with low BMI and two times higher in drivers with height under $1.58 \mathrm{~m}$. Regarding gender, women were more exposed to lumbar spine pathology, and had a two times higher risk of developing cervical spine pathology than men. [6] The association between height, weight and MSDs is partially related to the work post ergonomics, unsuitable for extremes. Inappropriate work postures are in relation to the adjustment difficulties of the driver's seat for extreme height and weight. [7] Individual genetic factors may also play a role in developing dorsopathies. Strenous physical activity, cigarette smoking and genetic factors are thought to increase the risk of disc herniation.[2]

In a prospective study, duration of professional driving and ergonomic risk factors were independent and preventable risk factors for low back injury even after adjustment for 
psychosocial factors. An exponential dose-response relationship was found between weekly driving hours and incidence of first low back injury. Moreover, indicators of physical workload were more strongly associated with more severe low back injuries (defined by the study as medically diagnosed postlaminectomy syndrome, spinal stenosis, herniated lumbar disc, sciatica or spinal instability). Rates of severe low back injury increased $39 \%$ for every 10 hours increase in weekly driving. Higher risks of severe low back injury were also found among drivers performing heavy physical labor on cable cars or reporting more ergonomic problems at baseline. [8]

Both physical workload and psychosocial factors were simultaneously and independently associated with back or neck pain in a cross-sectional study. Among the psychosocial factors were: extended uninterrupted driving periods, high psychological demands, high job insatisfaction, low supervisory support. [9]

In a prospective study, the low social support from the superiors and the decreased decisional capacity of drivers were predictive for cervical spine MSDs and to a lesser degree to lumbar spine MSDs, after adjustment for confounders. A significant dose-response relationship was found both between social support and cervical pain and between high psychological demands, respectively decreased decisional capacity and cervical pain. [10]

\section{Methodology}

The general methodology was complex, ergonomic [11] and followed:

- Technical-organizational and psychophysiological analysis of the activity for the studied groups and the conditions for carrying out the activity (environmental, organizational factors, work post ergonomics)

- Evaluation of physical and neuropsychic work related effort, of the workloads and of the work related stress

- Identification of the risk and stress factors of the human body, including ergonomical and psychosocial, that can generate MSDs and stress

- Analysis of the physical and mental health

- Establishment of prevention measures / reduction of risk factors and workloads

Methods used:

- Technical and technological documents study, job descriptions, analysis of developed activity / work task, work regime, working conditions (environmental factors, ergonomic analysis of work post)

- Medical and psychological files analysis

- $\quad$ Analysis of the results of risk level per work post / activity evaluation

- Questionnaires (e. g. CESP, COPSOQ), checklists, interviews

Choosing the package of techniques and tools (programs / scales / their individual elements) was made according to the stages of the study (e.g. TLX index for effort in carrying out the work task - TLX NASA, work capacity index, etc.).

\section{Results and discussion}

The results of the work post / activity global risk level evaluation shows that the investigated personnel is subject to an accumulation of occupational risk and workload factors. The major risk is represented by the road risk potentiated by specifics of urban traffic, the heavy traffic, 
weather conditions, the time at traffic lights, poor discipline in traffic, some passengers behaviour, poor infrastructure etc. Other risks that play an importat role are the physical, environmental and psychosocial work demands, and the ergonomic conditions of activity. Activity specific physical demands are the prolonged sitting posture (e.g. sometimes for more than two hours), flexions in the frequent rotation of the torso, the effort to activate the commands associated with whole body vibrations potentiated by ergonomic deficiencies of the driving post (e.g. small driver's cabin space, inadequate seats with adjustment problems, driver's seat suspension problems). A contribution in all three studied groups has also manual handling. Thermal discomfort, even stress in the driver's cabin is sometimes present (especially for tram and trolleybus). Psychosocial risks are related with activity specifics represented by repetitive and monotonous activity with increased level of vigilance, with permanent retrieval of information, with significant mental effort. Between the most important psychosocial risk factors possibly generators of stress are: the content of activity and its specific workloads (sensory-mental, cognitiv and emotional effort), the increased resposability in relation to traffic and passengers safety, the busier traffic, too long workshift and working week, the time pressure, work-family life imbalance, lack of autonomy, sometimes conflicting requirements (driving schedule, actual duration of the route and safety concerns), the decreased social support from the superiors. The contradictory requirements, resolved with or without driver's emotional involvement are felt as a psychic workload, stress, as inadequate. In this picture of global exposure and workload are included the occupational risk factors of MSDs: biomechanical factors in a repetitive manner, physical factors, the work organization, especially the daily and weekly duration of work, ergonomic and psychosocial risk factors.

From the evaluation of work related effort based on the subjective evaluation indicators (TLX-NASA) a high perceived level of total work related effort (TE) was obtained in all three studied groups. A high level of mental demands (MD), followed in descending order by temporal demands (TD) and physical demands (PD) were main contributors to the total work related effort in all three groups. The professional performance (PP) was in accordance with professional requirements, without contributing to additional effort. The frustration (Fr), as a state of tension felt during the work task performance, registered a medium level.

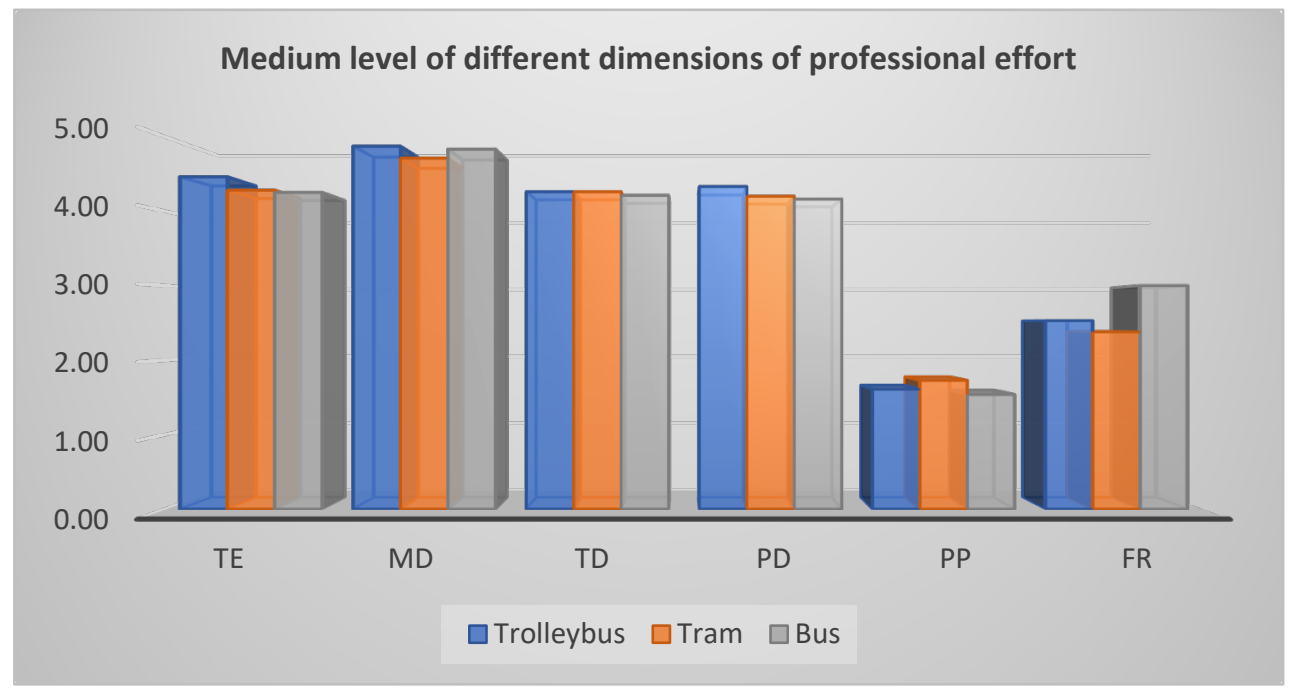

Fig. 1. The professional effort (TXL-NASA index) in the three studied groups 
The followig medical results were obtained in the studied groups:

In the group of trolleybus drivers there is a high percentage of spinal pathology, especially lumbar ( 24 people in the group have lumbar dorsopathy, respectively 2 people have also thoracic dorsopathy, and one person has also cervical dorsopathy in addition to the lumbar dorsopathy). Spinal pathology, including herniated disc, sets in early, starting in the 36-45 group. Disc herniation, present especially in the lumbar and lumbosacral spine, is also significant, meeting the criteria for occupational disease. However, only a part of the affected people choose to file an occupational disease (e.g. in the group of trolleybus drivers, out 7 people with herniated disc, only 3 have an occupational disease file).

Table 1. Distribution of dorsopathies of trolleybus drivers by age groups

\begin{tabular}{|l|l|l|l|l|l|}
\hline \multicolumn{1}{|c|}{ Age } & Participants & $\begin{array}{l}\text { Dorsopathies, } \\
\text { other than } \\
\text { herniated disc }\end{array}$ & $\begin{array}{l}\text { Herniated } \\
\text { Disc (HD) }\end{array}$ & \multicolumn{1}{|c|}{ HD \% } & $\begin{array}{c}\text { All } \\
\text { Dorsopathies } \\
\%\end{array}$ \\
\hline$<\mathbf{3 5}$ & 8 & - & - & - & - \\
\hline $\mathbf{3 6 - 4 5}$ & 13 & 4 & 2 & 15.38 & 46.153 \\
\hline $\mathbf{4 6 - 5 5}$ & 32 & 13 & 3 & 9.375 & 50 \\
\hline$>\mathbf{5 6}$ & 11 & 7 & 2 & 18.181 & 81.81 \\
\hline $\begin{array}{l}\text { All age } \\
\text { groups }\end{array}$ & 64 & 24 & $\begin{array}{l}7(6 \mathrm{M}, 1 \\
\mathrm{W})\end{array}$ & 10.937 & 48.43 \\
\hline
\end{tabular}

Table 2. Type of disc herniation in trolleybus drivers, function of gender and age

\begin{tabular}{|l|l|l|l|}
\hline $\begin{array}{l}\text { Crt. } \\
\text { Nr. }\end{array}$ & Type of disc herniation & Gender & Age \\
\hline 1 & $\begin{array}{l}\text { L4-5 DH (right and left, treated } \\
\text { surgically) }\end{array}$ & $\mathrm{M}$ & 42 \\
\hline 2 & L5-S1 DH (treated surgically) & $\mathrm{M}$ & 44 \\
\hline 3 & L4-5 DH & $\mathrm{M}$ & 47 \\
\hline 4 & L DH & $\mathrm{M}$ & 51 \\
\hline 5 & L5-S1DH (treated surgically) & $\mathrm{W}$ & 52 \\
\hline 6 & L DH (treated surgically) & $\mathrm{M}$ & 59 \\
\hline 7 & L5-S1DH (treated surgically) & $\mathrm{M}$ & 59 \\
\hline
\end{tabular}

The most frequent complain related to spondylosis (degenerative wear and tear changes in the spine) is axial spine pain concerning the low back, more than the neck and more than the midback. With irritation or compression of the spinal nerves, patients can develop tingling, burning sensations, loss of sensations, weakness and sometimes autonomic disfunction (most commonly difficulty with bowel ar bladder control). [2] Disc herniations, which are a frequent cause of sciatica are most common at L4-5 and L5-S1. A herniated disc caracteristically protrudes postero-laterally and impinges on the nerve that is migrating laterally to exit beneath the pedicle of the next lower vertebral segment. [2]

In the group of tram drivers, the spine pathology, especially lumbar, is significantly present (35 people in the group have lumbar dorsopathy, respectivelly 3 people also have cervical dorsopathy, and one person associates lumbar, cervical and thoracic dorsopathy; 6 people have cervical dorsopathy, and one person, thoracic). Spinal pathology, including herniated disc, sets in early, starting in the 36-45 group. Disc herniation, present especially in the lumbar and lumbosacral spine, but also in the cervical spine, is significant, meeting the criteria for occupational disease. 
Table 3. Distribution of dorsopathies of tram drivers by age groups

\begin{tabular}{|l|l|l|l|l|l|}
\hline Age & Participants & $\begin{array}{l}\text { Dorsopathies, } \\
\text { other than } \\
\text { herniated } \\
\text { disc }\end{array}$ & $\begin{array}{l}\text { Herniated } \\
\text { Disc (HD) }\end{array}$ & HD \% & $\begin{array}{l}\text { All } \\
\text { Dorsopathies } \\
\%\end{array}$ \\
\hline$<\mathbf{3 5}$ & 17 & - & - & - & - \\
\hline $\mathbf{3 6 - 4 5}$ & 36 & 12 & 2 & 5.555 & 38.888 \\
\hline $\mathbf{4 6 - 5 5}$ & 61 & 21 & 10 & 16.393 & 50.819 \\
\hline$>\mathbf{5 6}$ & 13 & 8 & 2 & 15.384 & 76.923 \\
\hline $\begin{array}{l}\text { All age } \\
\text { groups }\end{array}$ & 127 & 41 & $\begin{array}{l}14(2 \mathrm{~W}, 12 \\
\mathrm{M})\end{array}$ & 11.023 & 43.307 \\
\hline
\end{tabular}

Table 4. Type of disc herniation in tram drivers, function of gender and age

\begin{tabular}{|c|c|c|c|}
\hline $\begin{array}{l}\text { Crt. } \\
\text { Nr. }\end{array}$ & Type of disc herniation & Gender & Age \\
\hline 1 & $\mathrm{C} \mathrm{DH}$ & $\mathrm{M}$ & 42 \\
\hline 2 & L5-S1 DH (treated surgically) & $\mathrm{M}$ & 42 \\
\hline 3 & L4-5 DH (treated surgically) & $\mathrm{M}$ & 48 \\
\hline 4 & $\mathrm{~L} \mathrm{DH}$ & $\mathrm{M}$ & 50 \\
\hline 5 & L5-S1 DH (treated surgically) & $\mathrm{M}$ & 51 \\
\hline 6 & L DH (treated surgically) & $\mathrm{M}$ & 52 \\
\hline 7 & L DH (treated surgically) & $\mathrm{M}$ & 52 \\
\hline 8 & $\begin{array}{l}\text { L4-5 DH (treated surgically) } \\
\text { C DH (treated surgically) }\end{array}$ & $\mathrm{M}$ & 52 \\
\hline 9 & L5-S1 DH (treated surgically) & $\mathrm{M}$ & 52 \\
\hline 10 & L5-S1 DH (treated surgically) & $\mathrm{M}$ & 52 \\
\hline 11 & L5-S1 DH (treated surgically) & $\mathrm{M}$ & 55 \\
\hline 12 & L DH (treated surgically) & $\mathrm{M}$ & 55 \\
\hline 13 & L DH (treated surgically) & $\mathrm{W}$ & 57 \\
\hline 14 & L4-5 DH (treated surgically) & $\mathrm{W}$ & 59 \\
\hline
\end{tabular}

In the group of bus drivers there is a high percentage of spinal pathology, especially lumbar. Spinal pathology, including herniated disc, sets in early, starting in the 36-45 group. Disc herniation, present especially in the lumbar and lumbosacral spine, but also in the cervical spine, is significant, meeting the criteria for occupational disease.

Table 5. Distribution of dorsopathies of bus drivers by age groups

\begin{tabular}{|l|l|l|l|l|l|}
\hline Age & Participants & $\begin{array}{l}\text { Dorsopathies, } \\
\text { other than } \\
\text { herniated disc }\end{array}$ & $\begin{array}{l}\text { Herniated } \\
\text { disc (HD) }\end{array}$ & HD \% & $\begin{array}{l}\text { All } \\
\text { Dorsopathies } \\
\%\end{array}$ \\
\hline$<\mathbf{3 5}$ & 16 & - & - & - & - \\
\hline $\mathbf{3 6 - 4 5}$ & 53 & 9 & 5 & 9.434 & 26.415 \\
\hline $\mathbf{4 6 - 5 5}$ & 105 & 39 & 10 & 9.524 & 46.666 \\
\hline$>\mathbf{5 6}$ & 27 & 15 & 6 & 22.222 & 77.777 \\
\hline $\begin{array}{l}\text { All age } \\
\text { groups }\end{array}$ & 201 & 63 & 21 & 10.447 & 41.791 \\
\hline
\end{tabular}


Table 6. Type of disc herniation in bus drivers, function of gender and age

\begin{tabular}{|c|c|c|c|}
\hline $\begin{array}{l}\text { Crt. } \\
\text { Nr. }\end{array}$ & Type of disc herniation & Gender & Age \\
\hline 1 & L5-S1 DH (treated surgically) & M & 38 \\
\hline 2 & L5-S1 DH (treated surgically) & M & 42 \\
\hline 3 & L4-5 DH (treated surgically) & M & 44 \\
\hline 4 & L DH (treated surgically) & M & 45 \\
\hline 5 & C5-6 DH (treated surgically) & $\mathrm{M}$ & 45 \\
\hline 6 & L DH (treated surgically) & $\mathrm{M}$ & 46 \\
\hline 7 & L4-5 DH (treated surgically) & M & 47 \\
\hline 8 & L5-S1DH (treated surgically) & M & 49 \\
\hline 9 & L5-S1 DH (treated surgically) & M & 51 \\
\hline 10 & L DH (treated surgically) & M & 51 \\
\hline 11 & L4-5 DH (treated surgically) & M & 51 \\
\hline 12 & L DH (treated surgically) & $\mathrm{M}$ & 51 \\
\hline 13 & L5-S1 DH (treated surgically) & $\mathrm{M}$ & 51 \\
\hline 14 & L DH (treated surgically) & M & 53 \\
\hline 15 & L5-S1 DH (treated surgically) & M & 53 \\
\hline 16 & L DH (treated surgically) & M & 57 \\
\hline 17 & L4-5 DH (treated surgically) & M & 59 \\
\hline 18 & $\mathrm{~L} \mathrm{DH}$ & $\mathrm{M}$ & 60 \\
\hline 19 & L4-5 DH (treated surgically) & $\mathrm{M}$ & 61 \\
\hline 20 & L5-S1 DH (treated surgically) & M & 62 \\
\hline 21 & L5-S1DH (treated surgically) & $\mathrm{M}$ & 62 \\
\hline
\end{tabular}

From the literature we see that following nonsurgical treatment for lumbar disc herniation for over one year, the incidence of low back pain recurrence is at least $40 \%$ and is predicted by longer time to initial resolution of pain. Patients who undervent surgery for a lumbar disc herniation achieved greater improvement than conservatively treated patients in all primary and secondary outcomes except return to work status after four years follow up. [3]

On the whole, the tendency of the trolleybus drivers group, of not file an occupational disease, is preserved in the tram and bus drivers groups. Therefore, the statistics of occupational diseases do not reflect an exact figure of the professional pathology of the spine, the number of occupational diseases of the spine being underestimated. The percentage values of disc herniation are similar for bus drivers compared to those for tram and trolleybus drivers inthe studied groups, with slightly higher values in the case of the last two categories ( $10.5 \%$ in the case of bus drivers compared to $11 \%$ in the case of tram and trolleybus drivers). The highest percentage of dorsopaties was found in the over 56 years old group (oposed to 
the result of [6]), but the number of participants is small. Regarding the total percentage of dorsopathies, the highest levels are registered for trolleybus drivers $(48 \%)$, followed by tram $(43 \%)$ and bus drivers $(42 \%)$. It can be noticed that the percentage of dorsopathies is over $40 \%$ in all groups, for trolleybus drivers being higher than the upper limit of prevalence offered in literature (45\%) [3], and for tram and bus drivers slightly lower.

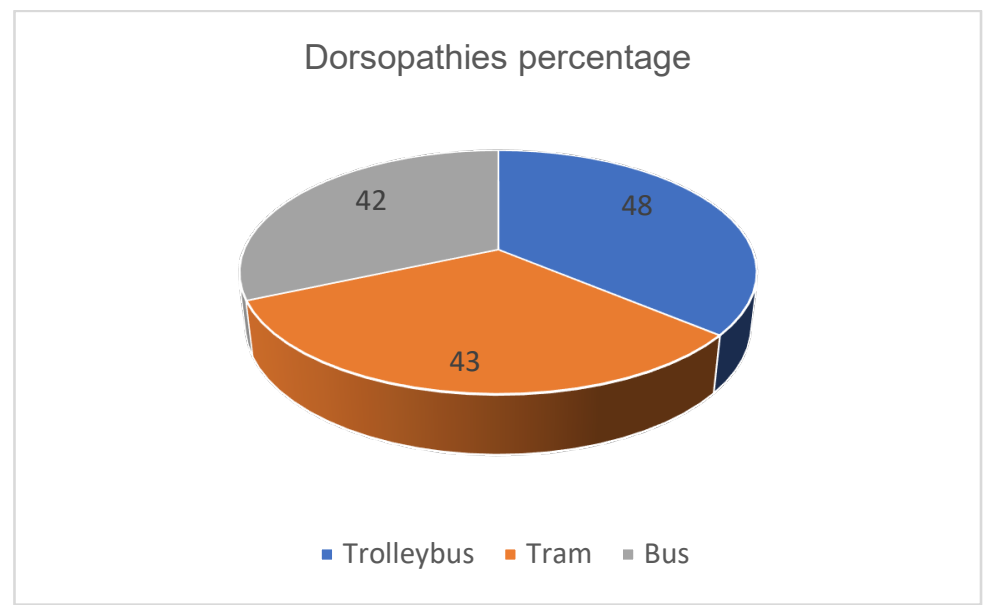

Fig. 2. Dorsopathies percentage in the three studied group

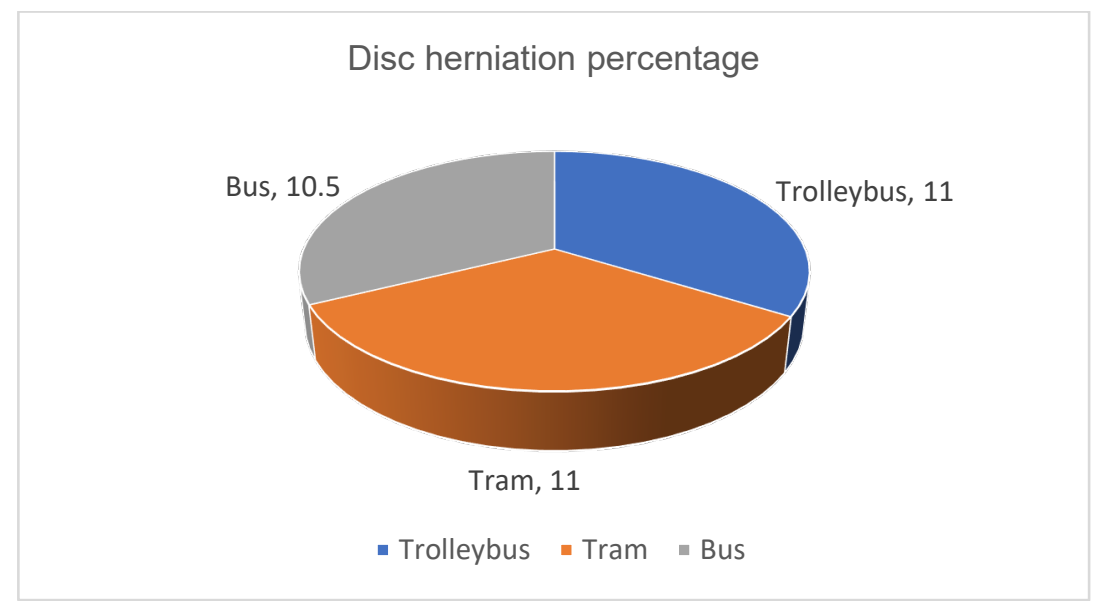

Fig. 3. Disc herniation percentage in the three studied groups

The following measures of prevention / reduction of identified risk factors are recommended: organizing the activity in relation to work and rest time, adaptating objectives and means in relation to work effort, organizational changes, ergonomic optimization of the work environment and workstation, reducing the duration of the shifts, application of technical measures to reduce the effort and stress at work, educational programs for adopting preventive behaviours regarding health at work (considerising also the increased age of wokforce), adopting coping and resistance to stress strategies, relaxation techniques, prevention of adictive behaviours, improving the psychosocial environment etc. 


\section{Conclusions and perspectives}

The study confirmed that MSDs ranks first in occupational pathology. In order to accurately establish the causal relationship between occupational risk factors and the vertebral column MSDs, a logitudinal study is needed. There is an upward trend in the prevalence of back pain in all three studied categories of public urban drivers. Spinal pathology, including herniated disc, sets in early, starting in the 36-45 group. This aspect can signalize early wear. The relatively small percentage differences of disc herniation between the three categories of personnel show that the development of this professional activity presents an increaesed risk of vertebral column MSDs production. It is absolutely necessary to apply the measures of primary/secondary prevention or reduction of the risk factors involveved in the production of MSDs like workplace proper ergonomics, work task organisation - by reducing the time pressure and job strain in general, and by offering enough break time for recovery -, and proper tretment of already established diseases insuring an optimal return to work.

\section{References}

1. J. Smedley, F. Dick, S. Sadhra (Eds), Oxford Handbook of Occupational Health, Oxford University Press (2013)

2. L. Goldmann, A. I. Schafer (Eds), Goldman-Cecil Medicine, Elsevier (2020)

3. J. LaDou, R. J. Harrison (Eds.), Current Diagnosis and Treatment. Occupational and Environmental Medicine, McGraw-Hill Education (2014)

4. S. Riviere, H. Prouvost, B. Sobczak, J. Plaine, L. Garrras, C. Pilorget, M. Valenty, Surveillance des maladies a caractere professionnel (Resultats 2007-2012). Chez les chaufeurs, MCP, Fevrier (2016)

5. OSH in figures: Occupational Safety and Health in the Transport Sector-An overview, EU-OSHA (2011)

6. N. Krause, D. R. Ragland, B.A. Greiner, J.M. Fisher, B. L. Holman, S. Selvin, Physical Workload and Ergonomic Factors Associated with Prevalence of Back and Neck Pain in Urban Transit Operators, Spine, 22 (18), 2117-2126, (1997)

7. M.F. Dartois, V. Ganndibleux, TMS et pathologies du rachis dans une population de conducteurs-receveurs d'une entreprise de transport urbain de voyageur, Arch Mal Prof Env, 67 (3), 545-546 (2006)

8. N. Krause, R. Rugulies, D. R. Ragland, S.L. Syme, Physical workload, ergonomic problems, and incidence of low back injury: A 7.5-year prospective study of San Francisco transit operators, American Journal of Industrial Medicine 46 (6), p 570585 (2004)

9. N. Krause, D. R. Ragland, B. A. Greiner, L. Syme, J. M. Fisher, Psychosocial job factors associated with back and neck pain in public transit operators, Scand J Work, Environ Health, 23 (3), 179-186, 1997

10. R. Rugulies, N. Krause, Job strain, iso-strain, and the incidence of low back and neck injuries. A 7.5-year prospective study of San Francisco transit operators, Social Science and Medicine 61 (1), 27-39 (2005)

11. R. M. Iordache, V. Petreanu, The Assessment of Mental Load of Air Traffic Controllers based on Psychophysiological Indicators, MATEC Web Conf, 290,12015 (2019) 